\title{
Outsourcing Model Evaluation for Business Process Management in Digital Economy
}

\author{
Lilyana Alekseevna Sosunova
}

Irina Valeryevna Yakhneeva

Anna Nikolaevna Agafonova

Samara State University of Economics, Russia, 443090, Samara, Sovetskoi Armii Street, 141, Correspondence Anna N. Agafonova Samara State University of Economics, 443090, Russia, Samara, Sovetskoi Armii Street, 141, Email: agafonova.a.n@gmail.com

\author{
Doi:10.5901/mjss.2015.v6n6s3p328
}

\section{Abstract}

The article is dedicated to the actual problems of the use of outsourcing model for business processes management in organizations. The objects of the research were the companies working in the sphere of electronic business: the developers of electronic services, trade enterprises, service aggregators sites. Electronic business is virtual and it is developing according to its own laws. Its main peculiarity is that the majority of business-processes are connected with information flows. They are less material than in traditional business. Companies' profit is created on the basis of the active involvement of informational resources. It was found out in practice that the outsourcing model is in demand in electronic business. The article reveals the concept of customer value taking into consideration the specific character of electronic business. A unique model of evaluation of advisability of full or partial use of outsourcing of business processes on the basis of complex evaluation of costs indexes and risks of a company. We suggest graphic interpretation of the author's model - a diagram of making decisions on transferring different informational business processes of a company to outsourcing on the basis of the identification of risk zones.

Keywords: outsourcing, digital economy, risks, customer value of outsourcing, business processes management.

\section{Introduction}

The possibilities to increase competitiveness, entering new markets, increasing of the effectiveness of work of the electronic business participants can be found in the use of outsourcing models of business processes and services. In general outsourcing is a management business model when part of business processes or production functions are transferred to another company to fulfill. The works of leading scientists such as R. Aalders, Ig.Ansoff, D. Brown, P. Gottschalk, J.Brian Heywood, R.Morgan, S.Wilson and others were dedicated to the research of this concept and the factors of attractiveness of outsourcing model.

The concept "outsourcing" was introduced in 1989 when the company Eastman Kodak attracted other organizations to purchasing, launching and maintenance of its systems of information processing. But the research of the experience of work of Henry Ford's plants in 20-30-s of the 20 th century and the German production enterprises in 50-s of the $20^{\text {th }}$ century testify the facts of use of outsourcing.

Outsourcing is a complex form of servicing the subjects of economic activities. Unlike traditional forms of service and business support which have occasional character, outsourcing is usually used for professional support of troublefree operation of individual systems and infrastructure of a company on the basis of a long-term contract. Nowadays the main types of outsourcing are as follows:

1. Manufacturing Outsourcing. It assumes that the company delegates the part of its chain of production processes (or even the whole entire cycle of production) to another company. There is an experience of selling a number of departments to other companies, and then the subsequent interaction with them is going directly within the framework of outsourcing. This type of outsourcing allows the company instead of solving routine tasks to focus on the development of entirely new products and services for competitive advantage, and increase manufacturing flexibility thanks to the restructuring of production and diversification of products.

2. Information Technologies Outsourcing. It is one of the most common types of outsourcing in today's world. The most popular services are: offshore programming (India, China, Russia and others.); production of web resources; development, installation and maintenance of software; the process of computer and nets 
maintenance by invited specialized organizations.

3. Business Process Outsourcing. It includes the use of third-party resources, skills, knowledge, abilities and experience, developed infrastructure of the service provider to resolve specific problems and achieve business goals of the organization. This type of outsourcing includes logistics outsourcing when the organization purchases from a third-party services of stock management, transportation management, storage of goods management and management of all business processes related to these operations.

4. Knowledge Process Outsourcing. It assumes control of processes that require in-depth study or serious analytical data, creating databases and their management, which subsequently can be used also for decision making support. In this case consulting companies are most frequently attracted as outsourcers.

Outsourcing models are diverse and determined by the amount and availability of connections between transmission functions: full outsourcing (there delegated the function as a whole or a complete set of operations); partial outsourcing (only part of specific tasks that are part of the business process is delegated); enhanced (managed) outsourcing (delegating certain functions to outsourcers, the company reserves the role of the controller and distributor).

Therefore, there arises an actual problem of research of the essence, advantages of outsourcing model for companies doing business in the e-economy, and the development of methodologies for assessing the feasibility of the transition to this model, taking into account internal and external factors of the enterprise work on the electronic market.

\section{The Methods of the Research}

Practice shows that in e-commerce outsourcing model is used more often than in traditional business. This is due to the specific character of the industry. The efficiency of any electronic trading platform, the website, is possible only with specialized infrastructure: technical, software, technology infrastructure, etc. The organizers of the business are usually owners competent in the field of product range, purchasing and cooperation with suppliers, the organization of sales and marketing. These are is the key business processes of e-commerce. But they are not possible without infrastructure support. Therefore, the primary reason of use of outsourcing model in e-commerce is delegating the range of issues to ensure the efficiency of the IT infrastructure.

In the process of development of e-business, managers of online shops face the problems of increasing the volume of routine operations, such as updating a virtual storefront, image processing, validating description of the goods, their characteristics, etc. It's a great demanding job that does not require highly skilled personnel. There are three possible solutions to the problem: the development of the software platform, that is, focus on the consolidation of database vendors and online stores. However, not all providers, and not all online stores are ready to do this. Many companies have just began moving to automation systems Enterprise Resource Planning, web-mastering technology integration; increase of staff and as a result an increase in expenses for salaries and contributions, the provision of social guarantees to the personnel, the need to implement measures to stimulate work, quality monitoring, etc .; appeal to the outsourcing model.

The next reason to use outsourcing model in e-commerce is associated with a high degree of innovativeness of the business. Virtual environment stimulates the increasing of the rate of innovation processes and reducing of the life cycle of goods and services. There are unique organizational structures: Internet incubators, business accelerators. Also in the Internet environment there is a high concentration of target groups: users of Internet services are more radical and receptive to new products than ordinary consumers. High dynamics of innovation processes creates quite a tense atmosphere for business owners on the Internet: they must constantly monitor the latest trends, find the most promising and interesting ones, introduce new technologies in their own businesses. Otherwise, the company will lose competitiveness in the near future. Thus, there is a need to outsource knowledge management, outsourcing of complex intellectual functions and operations, the effectiveness of which depends largely on the knowledge of certain secrets and know-how.

Demand for logistics outsourcing in e-commerce is mainly due to the resource advantages of service providers. First of all, these are industrial and technological or infrastructure resources. Creation and development of its own logistics infrastructure (storage, transport) requires significant investments. Outsourcing company may also have other resource advantages: geographical (network of distribution centers and points of orders delivery in a variety of cities and countries), trade (a unique experience on the market, knowledge of market conditions, etc.), innovative (unique equipment and technologies of making sets of orders, packaging, labeling, etc.).

Information and Technology outsourcing takes on new forms and is becoming more popular due to the spread of market technology Cloud Computing. This virtual model of IT-resources is gaining popularity due to the following advantages - rapid provisioning of resources and economic benefit - the user pays for the service only when it needs it, 
and the ability to save on the purchase, maintenance, software upgrades and equipment. Table 1.

The advantages of outsourcing on the basis of Cloud Computing technology for e-commerce are presented in

Table 1. The Advantages of Outsourcing on the Basis of Cloud Computing Technology for E-commerce.

\begin{tabular}{|l|l|l|}
\hline № & Advantage & Characteristic features \\
\hline 1 & Servicing when it is necessary & $\begin{array}{l}\text { Access to the computing resources is provided unilaterally, if necessary, automatically, with no interaction with } \\
\text { the staff of the service provider. }\end{array}$ \\
\hline 2 & Broad net access & $\begin{array}{l}\text { Computing resources are available on the network through a standard mechanism for a variety of platforms: } \\
\text { mobile phones, l-pads, laptops, desktops, etc. }\end{array}$ \\
\hline 3 & Uniting resources in groups & $\begin{array}{l}\text { The consolidation of computing resources of the provider to provide the service of many consumers according to } \\
\text { the model of the multiple lease. Lower total cost of services, the redistribution of power at peak load. }\end{array}$ \\
\hline 4 & Elasticity of service & Flexibility and adaptability of terms and volumes of the resources depending on demand. \\
\hline 5 & Measurability & $\begin{array}{l}\text { Functions of the automated measurement and evaluation of the services provided. Tools to optimize the use of } \\
\text { resources. Monitoring and control of information operations that provides transparency for both the supplier and } \\
\text { the consumer using the service. }\end{array}$ \\
\hline
\end{tabular}

All the above-mentioned reasons for the transition to outsourcing model in e-commerce have the principle of economic expediency in their basis, that is, the economic efficiency of the Internet company after the transition to the model would be higher than it was before transition. The estimated average time interval is from 3 to 18 months depending on the size of the company.

Strategy of outsourcing should be cost-effective for the company operating in the environment of e-commerce. Therefore, the economic rationale is usually carried out on the basis of cost-effectiveness model of outsourcing.

$$
E=\sum_{i=1}^{n} \frac{S_{i-1} P_{i}}{\left(1+\frac{d}{1000 \%}\right)^{i}}
$$

$E$ is economic effect from outsourcing; $n$ is the length of the period, during which it is supposed to use outsourcing; $\mathrm{Si}$ are expected costs of fulfilling the process by the company itself.; $\mathrm{Pi}$ is the full cost of the process if it is performed by the outsourcer in the year $i$ (includes the expenditures of the client on the interaction with the outsourcer) $d$ is the discount rate, $\%$.

To our point of view, the cost model to assess the feasibility of transition to outsourcing is unilateral, it does not account for the effects of organizational changes - namely, the economic risks associated with them.

There are specific factors in electronic business influencing the arising of risks (Table 2)

Table 2. Conditions and Factors of Arising of Risks in Electronic Business.

\begin{tabular}{|c|c|}
\hline $\begin{array}{l}\text { Specificity of electronic } \\
\text { business as economic activity }\end{array}$ & Conditions and factors of arising of risks \\
\hline 1 Global market space & $\begin{array}{l}\text { The conjuncture of the world economy } \\
\text { Currency fluctuations } \\
\text { International events } \\
\text { Changing conditions of cross-border logistics }\end{array}$ \\
\hline 2 Extraterritoriality & $\begin{array}{l}\text { Reducing the company's competitiveness on targeted localized markets due to the fact that the peculiarities of its } \\
\text { conjuncture were not taken into account }\end{array}$ \\
\hline $\begin{array}{l}3 \text { The prevalence of network } \\
\text { forms of organization }\end{array}$ & $\begin{array}{l}\text { Dynamic changes of the network structure } \\
\text { Unstable information ties } \\
\text { The lack of coherence of network participants }\end{array}$ \\
\hline 4 Virtualization & $\begin{array}{l}\text { The emergence of the threat of virtual fraud, data leakage, disclosure of trade secrets } \\
\text { Increasing of the value of transactions at changing the quality of } \\
\text { communications } \\
\text { Refusal of providers (service providers) to conclude contracts of } \\
\text { Maintenance; unacceptable for the company conditions of interaction }\end{array}$ \\
\hline $\begin{array}{l}5 \text { Low degree of tangibility of } \\
\text { commodity flows }\end{array}$ & Non-conformity of the goods with the quality requirements. The decision of consumers to switch to another vendor \\
\hline $\begin{array}{l}6 \text { The principle of open } \\
\text { information systems }\end{array}$ & $\begin{array}{l}\text { The outflow of customers with the appearance of negative information about the company and products } \\
\text { The vulnerability of the company during the crisis due to information openness }\end{array}$ \\
\hline 7 Customization & $\begin{array}{l}\text { The lack of opportunities to offer highly personalized service to certain groups of consumers, outflow of clients } \\
\text { The lack of institutional, industrial, investment resources to meet the differentiated demands of consumers } \\
\text { Inconsistency of the offered loyalty programs to the expectations of the customers }\end{array}$ \\
\hline
\end{tabular}


The specific character of e-business as the economic activity, as well as possible risks of the companies confirm the necessity to identify risks and their sources and to evaluate them.

In practice, as a rule, there is the following situation: choosing a model of partial outsourcing, the company decides what kind of business processes it will delegate to another organization. The transferring of some business processes will bring acceptable risk, and the transferring of others - a situation of critical or even unacceptable risks. So, we propose to introduce the factor of risk in the evaluation model and to take into consideration not only economic feasibility but also possible risks when analyzing the consequences of transiting to outsourcing.

The proposed methodology is based on the method of expert estimation that is the main risk parameters will be evaluated by the expert method, the integral index being the main value of risk assessment. Usually the formula of weighted evaluation is used:

$\mathrm{R}=\sum \mathrm{Wi} \mathrm{Pi}$

where $R$ is the integral level of risk,

$i$ is the number of identified risks,

$\mathrm{P}$ is the probability of arising/influence of risk,

$W$ is the level of significance of risks.

Let us use the method of evaluation of the integral indicator of risk. We suggest the following stages of analysis:

1) diagnostics of information and management business processes in order to identify potential risks;

2) the development of a list of risks possible when transferring business process for outsourcing;

3) evaluation of risk parameters and calculation of risk index;

4) construction of risks map that will be used to identify the most significant and influential risk zones.

The method is based on the assessment of risk parameters: danger, probability and frequency. Using the "incidence of the risk situation" parameter is explained by the fact that the traditionally used indicator of "probability" shows mathematical evaluation of the risk during the year, and the rate of "frequency" refers to the number of potential risk situations, based on a long period of time, "that is, the risk assessment becomes more adequately related to the time factor. The scale of risk frequency estimation is presented in Table 3.

Table 3 - The Scale of Estimation of Arising of Risk.

\begin{tabular}{|l|c|}
\hline Frequency & Estimation \\
\hline One occasion in 10 years & 0,0003 \\
\hline One occasion in a year & 0,0027 \\
\hline One occasion in half a year & 0,0055 \\
\hline One occasion in a quarter of a year & 0,0111 \\
\hline One occasion in a month & 0,0333 \\
\hline One occasion in a week & 0,1428 \\
\hline One occasion in three days & 0,4286 \\
\hline Daily & 1,0000 \\
\hline
\end{tabular}

The danger or the degree of risk influence shows how serious and devastating can be the consequences of outsourcing for a virtual commercial company. The risk can be described as the seriousness of the consequences, taking into account the possibilities of the error correction and its cost. There are different ways of assessing risk. We recommend to evaluate this parameter on a scale as the main task of the analysis is to identify the risk areas to select from alternatives: pass or not the process of outsourcing. Point method in expert assessments allows you to get an adequate result and in a simple manner creates a picture of differentiation danger of the identified risks.

This method is complex, gradual and takes into account the most important factors in evaluation of the parameters affecting the efficiency of business process management.

\section{Results}

On the basis of summarizing current trends in the development of outsourcing the following factors forming the value of outsourcing in electronic business were highlighted:

- unique technologies, know how, patents, licensees of the company-outsourcer;

- developed infrastructure of the outsourcer;

- the possibility of optimization of IT-infrastructure and virtual business services on the basis of new 
technologies;

- getting rid of routine operations, reducing staff.

In the future, it will make possible to determine the criteria of effectiveness of using this model on the basis of the peculiarities of functioning of the enterprise and its resource capabilities.

Two-factor model-map on making a decision on transiting the part of business processes to outsourcing, Figure 1.

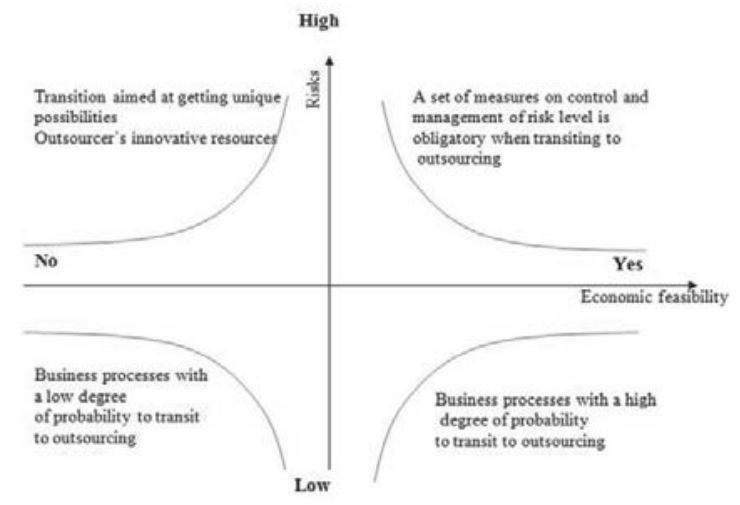

Figure 1. Diagram of Making a Decision to Transit Part of Business Processes to Outsourcing.

On the map there are highlighted four areas, evaluating the combination of the level of risk and the availability of the economic feasibility of transition to partial outsourcing. At the same time, the economic feasibility is viewed as the ratio of $\mathrm{Pi}$, - the total cost of the process when it is performed by the outsourcer in the i-th year, including the costs of the customer to interact with the outsourcer, (monetary units) to the $\mathrm{Si}$ - the expected costs to perform the process on their own in the i-th year (monetary units).

1. For companies working in the field of e-business there are determined the parameters of the assessment of the risk from the transition of information business process to outsourcing (Table 4).

Table 4. Determination of Risk Zones when Transiting Information Business Processes to Outsourcing.

\begin{tabular}{|c|c|c|c|c|c|}
\hline \multirow{2}{*}{ № } & \multirow{2}{*}{\begin{tabular}{|l|} 
Business process (service) \\
Risks
\end{tabular}} & \multicolumn{4}{|c|}{ Параметры оценки риска } \\
\hline & & Danger, score & Probability, share & Frequency & Index of risk \\
\hline 1 & 2 & 3 & 4 & 5 & 6 \\
\hline \multicolumn{6}{|c|}{\begin{tabular}{l|l}
1 & IT-infrastructure management
\end{tabular}} \\
\hline 1.1 & Mistakes in the work of users during operations & 8 & 0,4 & 0,0333 & 0,1066 \\
\hline 1.2 & Failure in the work of apps of the Internet shop management & 9 & $\overline{0,4}$ & 0,0111 & 0,04 \\
\hline 1.3 & Stopping of business processes & 10 & 0,7 & 0,0111 & 0,0777 \\
\hline 2 & \multicolumn{5}{|l|}{ Information flows/content management } \\
\hline 2.2 & The unreliability of the information posted on the website & 4 & 0,15 & 0,1428 & 0,0857 \\
\hline 2.3 & Reduced responsiveness of updating & 3 & 0,37 & 0,0333 & 0,037 \\
\hline 3 & \multicolumn{5}{|l|}{ Communication with consumers, including call-centres } \\
\hline 3.1 & The loss of part of the customers because of improper servicing & 5 & 0,25 & 0,1428 & 0,1785 \\
\hline 3.2 & Decrease of orientation towards clients & 7 & 0,5 & 0,0111 & 0,0389 \\
\hline 3.3 & Unauthorized transfer of the data of "customer base" to third parties & 9 & 0,2 & 0,0027 & 0,0049 \\
\hline 4 & \multicolumn{5}{|l|}{ Monitoring and analysis } \\
\hline 4.1 & Reduced operational monitoring and identification of problematic situations & 6 & 0,3 & 0,0333 & 0,0599 \\
\hline 4.2 & Incompetence of analytical conclusions & 8 & 0,4 & 0,0111 & 0,0355 \\
\hline 4.3 & Disclosure of trade secrets & 10 & 0,2 & 0,0027 & 0,0054 \\
\hline 5 & \multicolumn{5}{|l|}{ Internet promotion } \\
\hline 5.1 & Increased costs of marketing promotion & 7 & 0,5 & 0,0111 & 0,0389 \\
\hline 5.2 & Reduced customer loyalty because of the mistakes of market specialists & 5 & 0,5 & 0,0333 & 0,0833 \\
\hline 6 & \multicolumn{5}{|l|}{ Audit and consulting } \\
\hline 6.1 & Reduced effectiveness of project management & 7 & 0,7 & 0,0333 & 0,1632 \\
\hline 6.2 & Tax risks & 7 & 0,5 & 0,0111 & 0,0389 \\
\hline
\end{tabular}


We have identified the most important business processes of companies operating in the e-business environment. To a large extent they relate to the operations of collection, transmission, intelligent processing of information. These are: ITinfrastructure management, information/content management, communication with customers, monitoring and analysis, Internet promotion, auditing and consulting. We determined the parameters of risks evaluation aimed at the calculation of the integral index of risks.

1. Using the method of expert assessment we determined risk areas of the key business processes of companies operating in the e-business.

Table 5 presents the indicators to assess the feasibility of outsourcing analyzed business processes of the Internet company.

Table 5. Parameters of estimation of the feasibility of outsourcing the Internet company business processes.

\begin{tabular}{|c|l|c|l|}
\hline$№$ & Business processes & Economic feasibility & Risk zone (revealed maximum index of risk) \\
\hline 1 & IT-infrastructure management & 1,94 & Zone of high risk $(0,1066)$ \\
\hline 2 & Information flows management & 1,83 & Zone of acceptable risk $(0,0857)$ \\
\hline 3 & Communications with consumers & 1,67 & Zone of high risk $(0,1785)$ \\
\hline 4 & Monitoring and analysis & 1,04 & Zone of acceptable risk $(0,0599)$ \\
\hline 5 & Internet promotion & 1,42 & Zone of acceptable risk $(0,0833)$ \\
\hline 6 & Audit and consulting & 1,48 & Zone of high risk $(0,1632)$ \\
\hline
\end{tabular}

On the basis of this table there was compiled the chart on making the decision to transit the information business processes to outsourcing (Figure 2), clearly reflecting the results of the author's methodology.

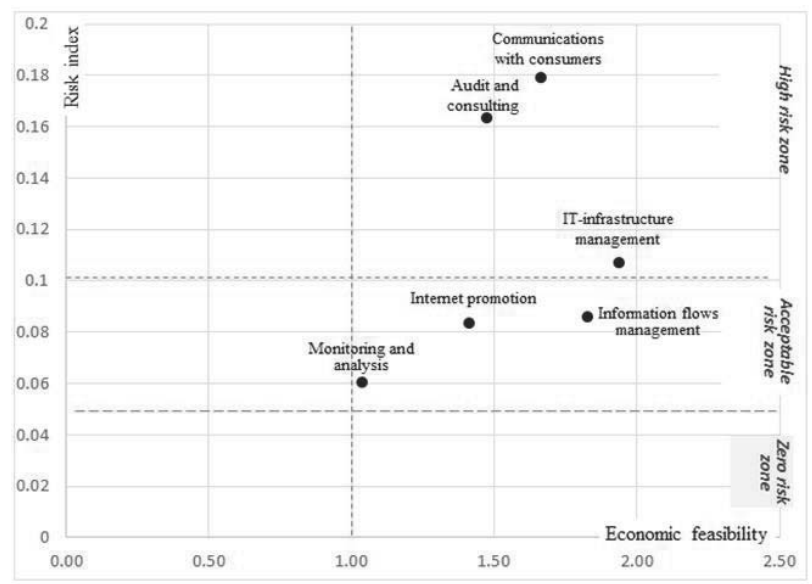

Figure 2. The diagram of making a decision to transit information business processes to outsourcing

Determination of risk zones was based on the designation of their intervals depending on the value of risk index. Evaluation of the economic feasibility of outsourcing was calculated on the basis of assessment method TCO (total cost of ownership). There were identified direct and indirect costs of the business processes of the e-commerce company. In particular, costs related to the remuneration of staff with different skills, the cost of information resources, the cost of the use of computer hardware, software, networking, training costs, etc. The factors of the IT-outsourcing services market conjuncture and the conjuncture of the market of the RF Internet projects management (January-July 2014) were also taken into consideration.

According to the data received, the majority of the analyzed business processes of the companies are located in the zone of acceptable risk when transferred to outsourcing and economic feasibility coefficient is bigger than 1 . This means that on today's market there has been formed a competitive offer of services to support online businesses. And the model of outsourcing is not only economically feasible but also does not cause high risks for companies that transit business processes to outsourcing. 


\section{Discussions}

The proposed model of evaluation of business process outsourcing is based on the analysis of indicators of costs and risk indicators of the company operating in the field of e-economy. We see the prospects for the development of this model in the transition from two-factor estimation model to the three-factor estimation model. We believe that the effective indexes reflecting capacity or the degree of achievement of the targets of business in the transition to outsourcing may be the third factor. Perhaps such model will be based on the system of factors forming the value of outsourcing in e-business which was presented in the article.

Also, in our opinion, it is important to stress the universal nature of the proposed model to assess the feasibility of transition to outsourcing of business processes. In this article the study was conducted on the basis of the specific character of e-business. However, the I estimation algorithm and proposed methodology can be used by any of the companies whose executives solve the dilemma of the choice of full or partial outsourcing of production, service, information or logistics processes.

\section{Conclusion}

Today, outsourcing is a flexible, efficient model of business management. Market research of outsourcing services in the field of information management, as well as the results of the assessment of costs of electronic companies, show the usefulness of recourse to this model. However, in practice the question arises : how big is the risk of transition of a business process to a third party.

After analyzing the model of value of outsourcing in e-business, including the infrastructure, intellectual, resource advantages of the outsourcing company, we have come to the conclusion that in different cases the company is exposed to various risks. The principle proposal of this research is a comprehensive assessment of the appropriateness of outsourcing model for managing information processes in e-business. We have also established that both with full and partial outsourcing, cooperation between the parties must be accompanied by regular checks of performance, current assessment of risks and audit. Taking into consideration the long-term character of relations in the outsourcing model, the role of the current monitoring and control effectiveness of the parties increases. Since most Internet companies are working on the basis of multi-platform, having in their arsenal functions of planning, monitoring, analysis and control, the best option may be to consider the integration of these capabilities with the functionality of automation systems providers (outsourcers). It is also advisable to study the existing practices of e-commerce and innovative proposals, to develop and introduce new effective methods to improve the quality and reduce the costs of enterprises.

\section{References}

Fedorenko, R. V. (2014). Development of Outsourcing in the Customs Sphere. Asian Social Science; Vol. 10, No. 20; 2014, pp.202209.

Meeker, M. Internet Trends. Web 2.0 Summit. San Francisco, CA. [Electronic Resource] / M. Meeker. -Access Mode: http://www.kpcb.com/insights/2011-internet-trends. - title from the screen.

Porter, M. Strategy and the Internet [Text] / M. Porter.- Harvard Business School, 2001.

PriceWaterhouseCoopers E-Business made in Switzerland, Zürich, p.5. [Electronic Resource]. -Access Mode: http://www.pwcglobal. $\mathrm{com} / \mathrm{ch} / \mathrm{ger} / \mathrm{ins}$-sol/publ/ebiz/ebizmadeinch.pdf. -title from the screen.

Rosenblum, P., Omni-Channel 2013: the Long Road to Adoption. 2013 Benchmark Report, June 2013 [Electronic Resource]/P.Rosenblum,B.Kilcourse. - Access Mode: http://rsrresearch.com/wpcontent/uploads/2013/06/2013_XChannel_rpt_ RSR.pdf. - title from the screen.

Wilmot, J. Outsourcing Is Key to Surviving the Downturn: The Capgemini Executive Outsourcing Survey Conducted by Harris Interactive. Capgemini, 2009.

Agafonova A.N., Fedorenko R.V. The Development of Information and Logistics Infrastructure of E-commerce as the Factor of Intensification of the Regional Retail Trade [Text] // Bulletin of Samara State University of Economics, 2013. № 10 (108)p. 109112.

Agafonova A.N. Information Service in the Internet Economy [Text] /Agafonova A.N.. M.:BIBLIO-GLOBUS, 2014. p.152

Anikin B.A. Outsourcing and outstaffing: High Management Technologies [Text] / Anikin B.A., Rudaya I.L. - M.: Infra-M, 2009.

Bravar Zh.L., Morgan R. Effective Outsourcing. Understanding, Planning and Use of Successful Outsourcing Relations. - M.: Balance Business Books, 2007.

Gottshalk P. IT-Outsourcing: Building up a Mutually Beneficial Cooperation [Text] / Gottshalk P. - M: Alpine Business Books, 2007.

Evtodieva T.E. The Peculiarities of Organizational Forms of Logistics in Conditions of Neoeconomy [Text]: monograph / Evtodieva T.E. Самара: Publishing House of Samara State University of Economics, 2011. 
Haksever K. Management and Organization in the Sphere of Service [Text] / Haksever K., Render B., Rassel R., Merdik R.- the second edition-translation from English. Edited by Kulibanova V.V. - Saint Petersburg, p. 202. - 752 Heywood G.B. Outsourcing: Searching for Competitive Advantages [Text] / Heywood G.B. - M: "Williams", 2004.

Shadrin V.G. Outsourcing: Processes Management and Formation of Regional Centre [Text]: abstract of the Candidate of Economic Sciences /Shadrin G.V. - Kemerovo, 2006. - p.22

Yakhneeva I.V. Modeling and Designing of Delivery Systems in Conditions of Risk [Text]: monograph/ Yakhneeva I.V. - M: Biblioglobus, 2013. - p.176 